\title{
TECHNO-ECONOMIC ANALYSIS OF THE RECONSTRUCTION OF CENTRAL HEATING SYSTEM IN THERMAL POWER PLANT BITOLA
}

\author{
by \\ V.I. Mijakovski, T.B. Geramitcioski, V.B. Mitrevski \\ University "St. Kliment Ohridski", Faculty of Technical Sciences, Makedonska falanga 33, \\ Bitola, Republic of Macedonia \\ Professional paper \\ DOI: 10.5937/termoteh
}

With the latest modernization and revitalization of blocks in Thermal Power Plant (TPP) Bitola (2010-2012), apart from increasing the power of each unit from 225 to 234,3 MWel, new regulating valves were installed in the section between Medium Pressure Turbine (MPH) and Low Pressure Turbine (LPT) enabling subtraction of steam for the purposes of district heating of Bitola. This also creates opportunity to connect power plant's own central heating system, with installed heat capacity of approximately 26 MWh, to this heat source. This heating system is in operation for almost 35 years and the need for its revitalization and reconstruction, techno-economic analysis, investment costs, economic viability and return on investment period for the reconstruction are presented in this paper.

Key words: Power plant, heating system, analysis.

\section{INTRODUCTION}

Thermal Power Plant (TPP) Bitola is the largest electricity producer in Macedonia. So far, since the commence of its operation, the power plant was modernized two times. In 1994-1996 the installed capacity of each power unit was raised from the original $210 \mathrm{MW}_{\text {el }}$ to $225 \mathrm{MW}_{\text {el. }}$ Latest modernization $(2010-2012)$ raised the capacity to 233,4 MWel. This modernization included installation of regulating valves on units 2 and 3, between Medium

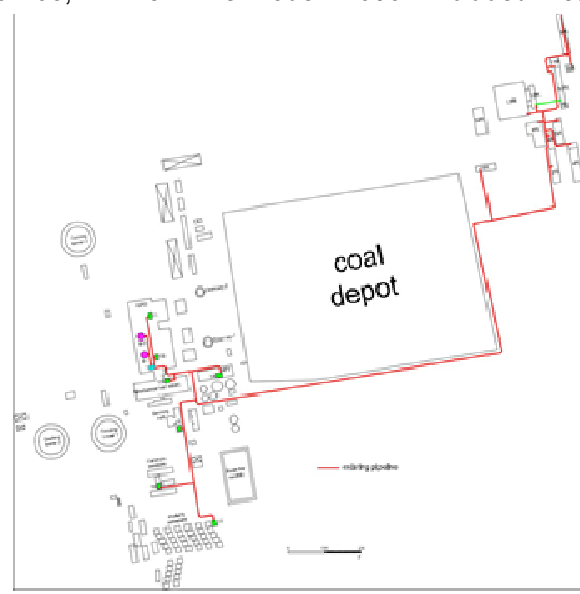

Figure 1. Existing pipeline in TPP - Bitola Pressure Turbine (MPT) and Low Pressure Turbine (LPT) in order to enable steam subtraction for district heating of the city of Bitola. It is foreseen that the subtracted steam will provide heat energy of 200MWh. Part of this heat (26 $\mathrm{MWh}$ ) will be used for central heating of buildings in the power plant, [1, 2]. Feasibility study, [3], was prepared in order to identify condition of the equipment at heating system for the buildings, research the possibilities for its revitalization/reconstruction and to give cost estimate for such a reconstruction.

According to current division and spatial disposition of facilities in TPP Bitola, for complete heat energy supply to its facilities, heating pipeline starts from the Main Production Object (GPO) and it's routed above ground, on pipe bridge up to seven heating substations in the Thermal Power Plant (TPP) and up to the consumers in the Mine, directly connected to the pipeline, Figure 1. 
Condition of the existing pipeline together with other elements forming the central heating system was also

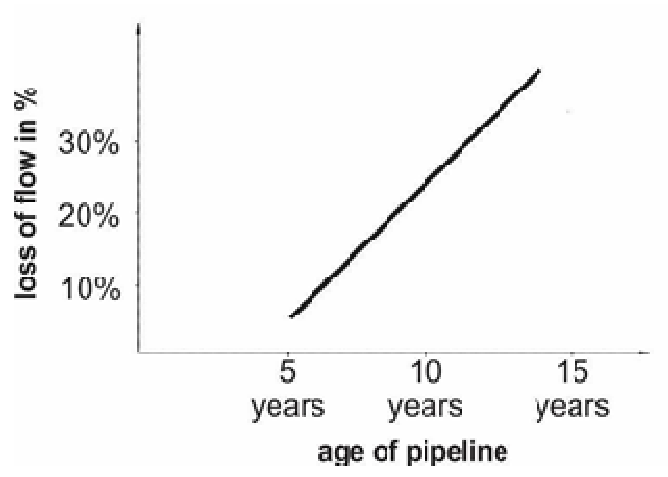

Figure 2. Deterioration of pipeline's throughput depending on exploitation period examined. From the existing project documentation, it is apparent that the heating pipelines are in exploitation for a long period of time (more than 30 years). Of course, operating condition is with very low energy efficiency (we can say 'without' energy efficiency).

According to published research of the pipelines condition $[4,5]$, for 7 years of exploitation, throughput (volume or mass flow) is reduced by $10 \%$, for 9 years of exploitation the throughput is reduced by $20 \%$, and for approximately 12 years of exploitation it is reduced by $30 \%$.

This tendency for reduction in volume or mass flow depending on the years of exploitation is illustrated in Figure 2.

Hence, the conclusion draws itself: existing pipelines are not suitable for further operation and should be replaces with new ones, using the same pipeline routes (layout).

\section{PROPOSED SOLUTIONS FOR RECONSTRUCTION OF THE NETWORK}

Newly proposed solution is based on installed heating capacity upon which for the complete supply of heat energy for heating of buildings in TPP-Bitola, in phase one, complete reconstruction primary pipeline network is proposed by construction of two new pipelines, Figure 3 - option with a total of 17 heat substations and Figure 4 option with a total of 9 heat substations for the power plant.

Regarding heat source, three options for connecting of the pipeline with the newly assigned heat source (6th steam subtraction from turbine, instead of 4th and 5th subtraction, as is the case now) were also proposed. The connection to the existing heat source (own needs' boilers) should also be kept as an option in a case of failure of other heat supply, [6].

Option 1, Figure 5, consists of keeping the same heat energy source (boiler for own needs in Block-1 and Block-2) with replacement of the pipelines (heat regime is changed from the existing $130 / 70^{\circ} \mathrm{C}$ to calculated one $110 / 70^{\circ} \mathrm{C}$ ). New circulation pumps, hydraulic junctions and new pipeline pumps (TP1, TP2 and RP1) are also proposed.

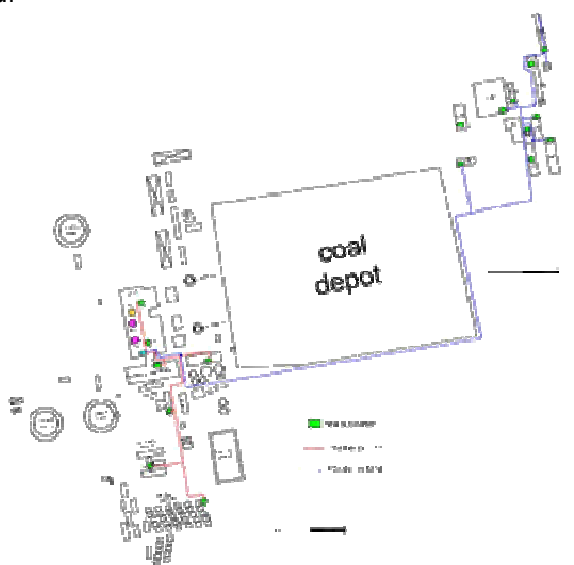

Figure 3. Synthesis layout of buildings and proposed solutions for pipelines in TPP - Bitola with a total of 17 heat substations

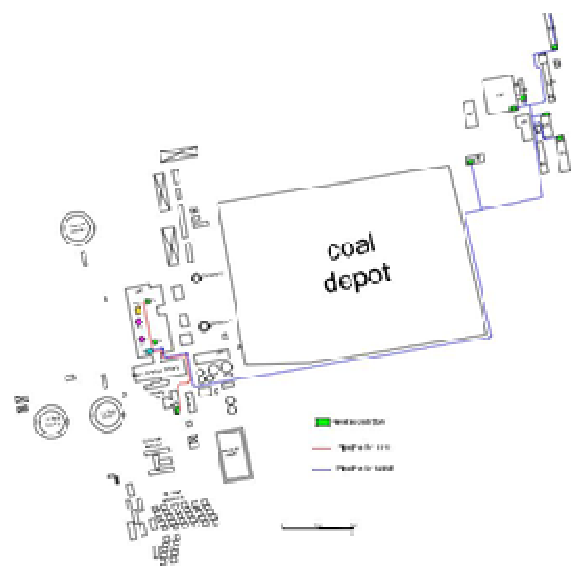

Figure 4. Synthesis layout of buildings and proposed solutions for pipelines in TPP - Bitola with a total of 9 heat substations

In the 2nd option, connection to the newly designed District Heating (DH) system of Bitola is realized through hydraulic junctions. Existing heat source for heating buildings in REK - Bitola is also in function, Figure 6. 


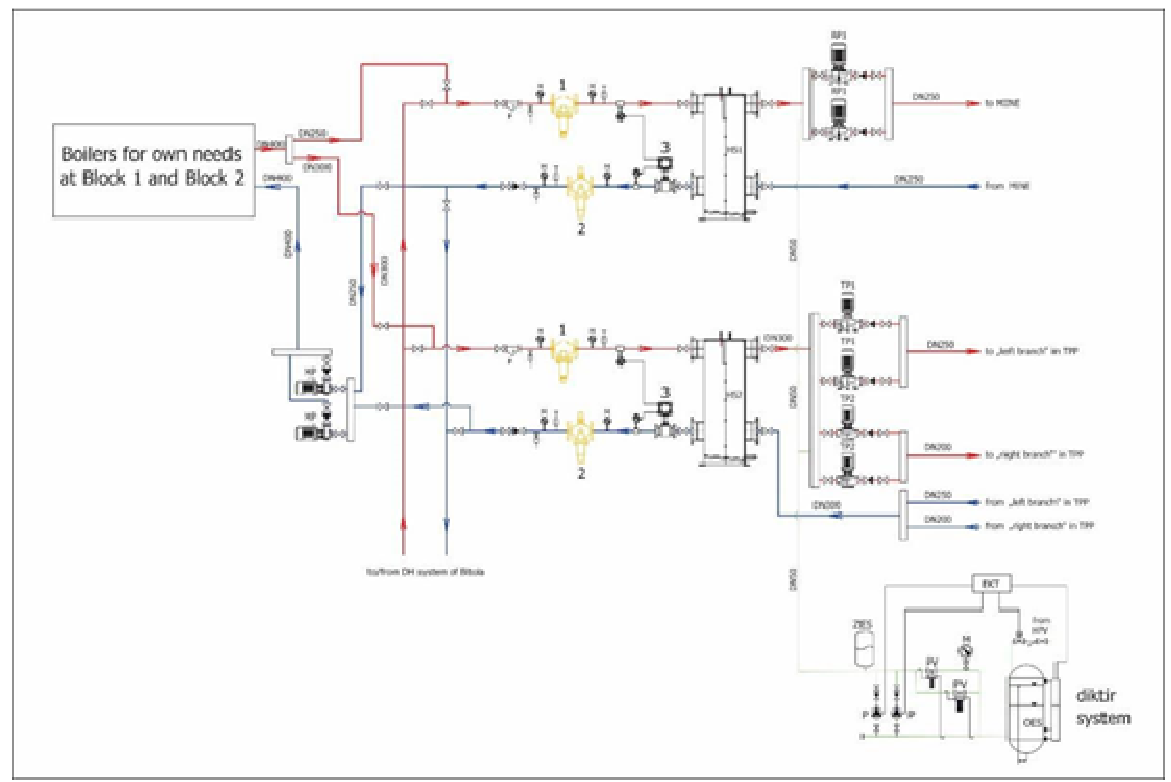

Figure 6. Option 2 - Schematics of connection for central heating systems of REK - Bitola to the newly designed DH system of Bitola

Primary heat transfer medium (water) from the $\mathrm{DH}$ system is separated from the hot water circulating in pipelines for heating of buildings in TPP Bitola in the 3rd proposed option. separation is done by a means of 2 Plate Heat Exchangers (PHE), one for Thermal Power Plant and one for MINE, Figure 7.

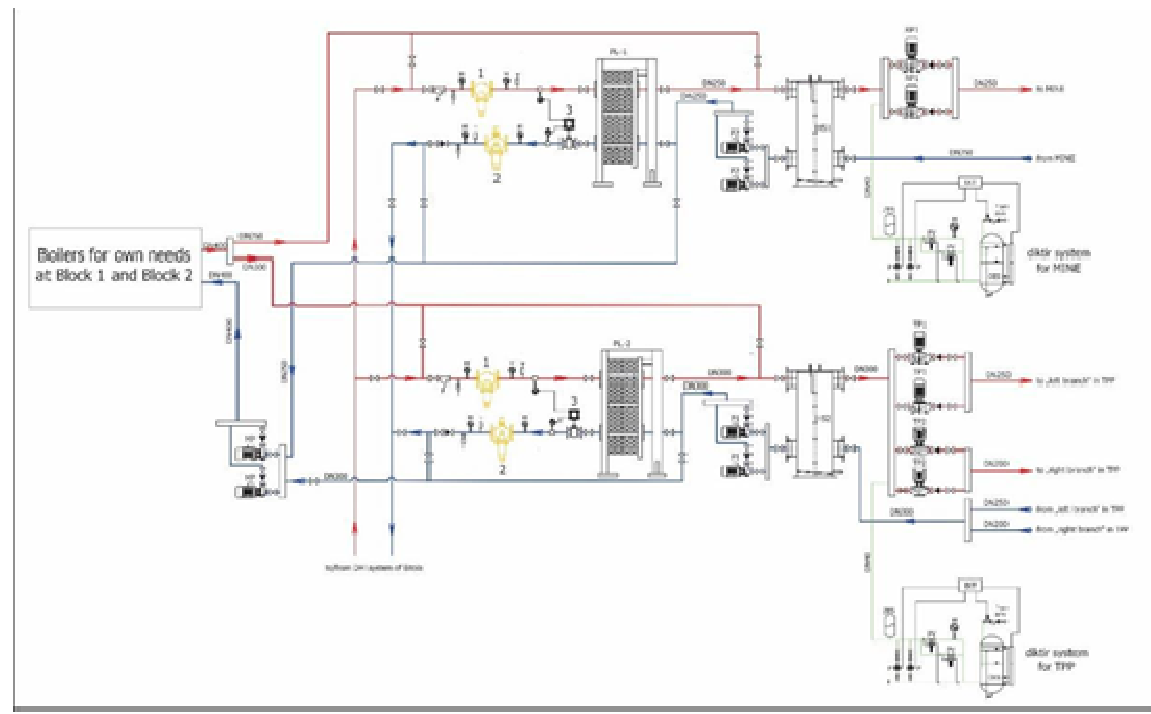

Figure 7. Option 3 - Schematics of indirect connection of systems for heating of buildings in TPP and MINE, to the newly designed DH system of Bitola through separate PHE

Third option enables autonomous operation of systems for heating buildings in TPP and MINE. Both systems are completely "independent" between themselves and with possible interconnection in the event of a major 
accident in some of the heat sources. This option is characterized with the feature that there is no mixing of network hot water from pipelines of TPP and MINE with the hot water from DH system of the city of Bitola.

HYDRAULIC CALCULATIONS AND TECHNO-ECONOMIC ANALYSIS OF NEWLY PROPOSED SOLUTIONS

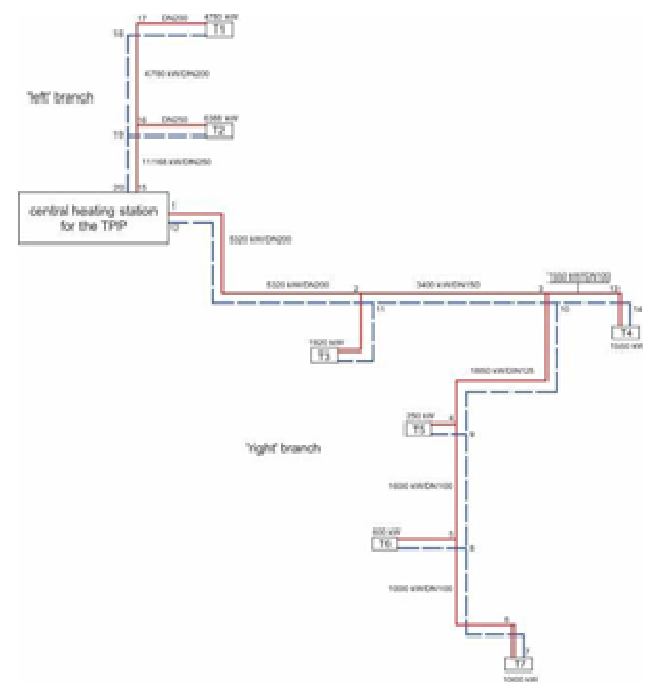

Figure 8. Schematics of pipeline and heating substations for TPP, Variant 1
Distribution of heat energy to consumers at district heating $(\mathrm{DH})$ systems mainly depends on the correct hydraulic calculation of the pipe network and other elements and units in the system, [7, 8]. For a certain area where $\mathrm{DH}$ should be implemented, characterized by certain terrain configuration, disposition of heating substations with certain heat load as well as with geodetic profile of the network, hydraulic calculation determines all relevant parameters for selection of installations and equipment of the pipeline, such as: pipe diameter, pressure drop, pressure in different points in the system etc.

Calculation of the pipeline network - heating pipelines is based on the principle of determination of pressure drop in the pipeline. The diameter of the pipeline has also been determined.

Calculations are performed for two variants of the main pipeline, first one with a total of 17 heat substations connected to it ( 7 in the power plant and 10 in the mine), and the second one with a total of 9 heat substations connected to it ( 3 in the power plant and 6 in the mine). Example of the basic flowconstructive characteristics by sections and heat substations for variant 1 in the TPP, are given in Figure 8 .

In order to prepare analysis of the return of investment (ROI) period of the whole reconstruction with regards to connection on the heat source at different subtraction point, a thorough calculation of all heat substations together with the main pipeline and central heating substations were performed.

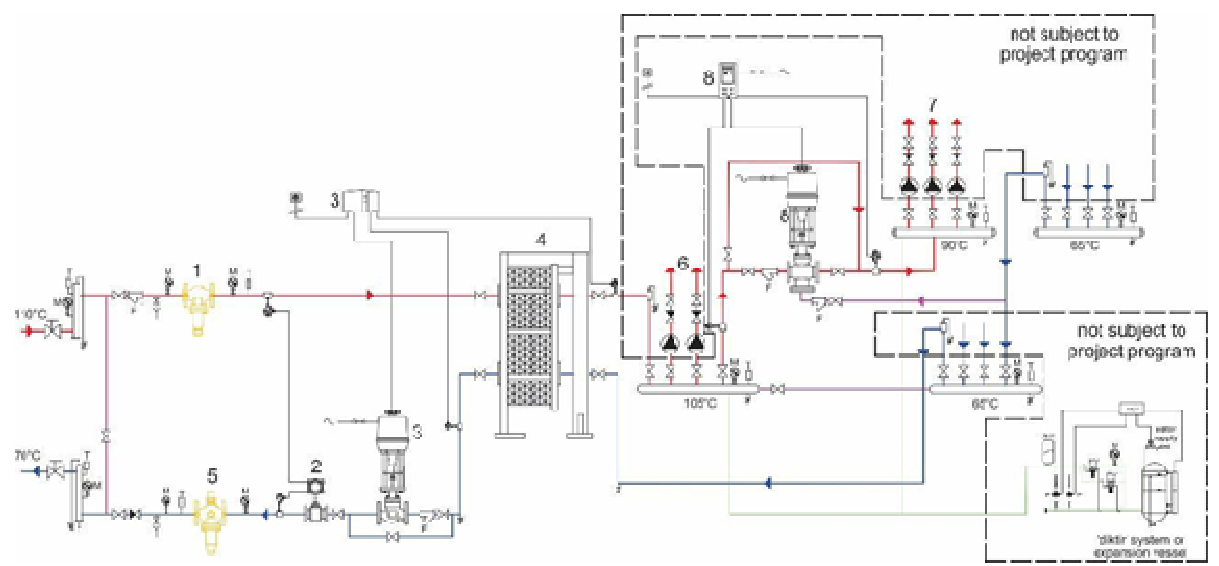

Figure 9. Heat substation T1: 1 - pressure regulator; 2 - set for measurement of consumed heat energy - heat meter; 3 - set for regulation of temperature in the total secondary loop, 2-way electro-motor valve with remote monitoring and control, compatible with $\mathrm{DH}$ system of Bitola; 4 - plate heat exchanger with $4800 \mathrm{~kW}$, primary side $110 / 70^{\circ} \mathrm{C}$, secondary side $65 / 105^{\circ} \mathrm{C}$, with dimensions $\mathrm{HxWxL}: 2400 \times 500 \times 1200 \mathrm{~mm}$; 5 - flow regulator; 6 set of pumps for transportation of hot water to heaters; 7 - set of pumps for transportation of hot water to radiators, 8 - set for regulation of temperature of secondary loop (radiators), 3-way mixing electro-motor valve with remote monitoring and control, compatible with $\mathrm{DH}$ system of Bitola 
Each proposed heat substation is standardized in terms of equipment and materials used, [9-11]. Some of the elements were not considered, since it was not subject to the project program. View of a heat substation is given in Figure 9.

Figure 10 shows heat scheme and location of steam subtractions after modernization - current state (situation d), [12]. The subtracted steam goes into two heat exchangers, each with 50MW heat power intended for heating of Bitola and heat energy requirements of TPP Bitola.

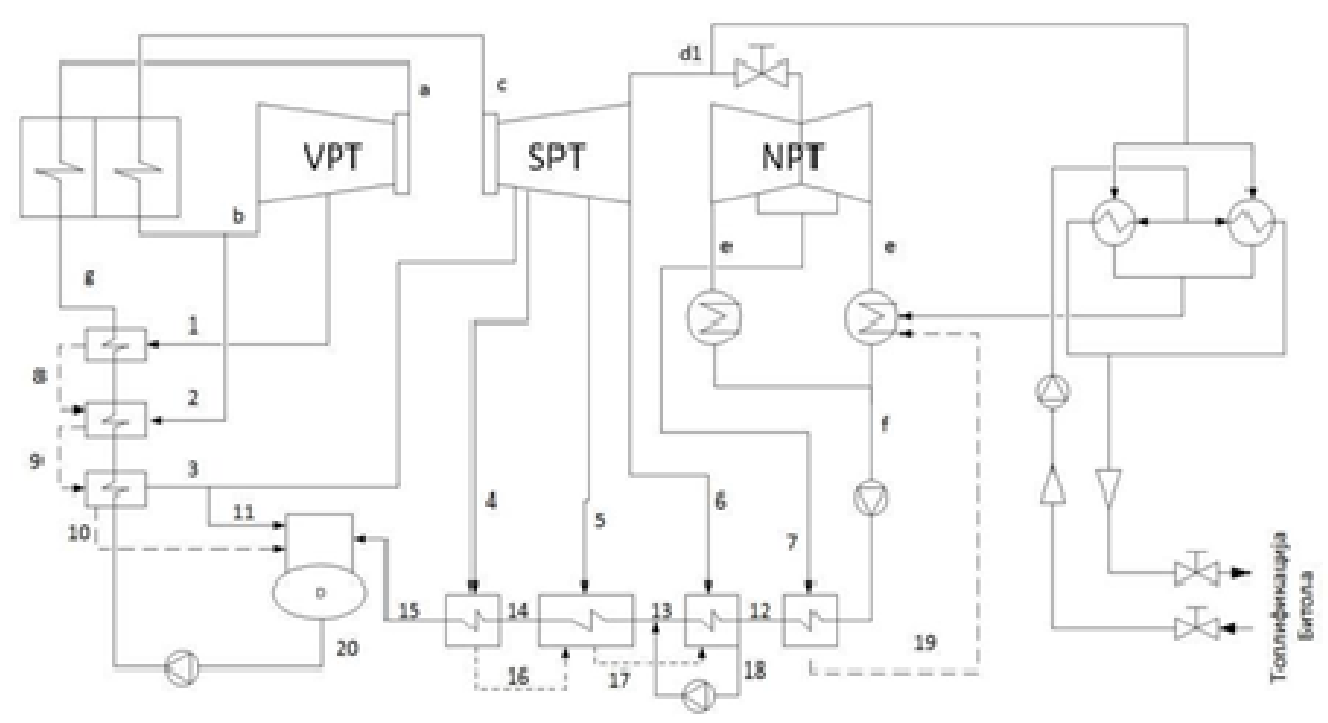

Fig. 10. Heat scheme of the turbine with steam subtractions for district heating of Bitola

Losses due to non-produced electricity as a consequence of subtracted heat for heating of TPP Bitola are obtained as a product from losses of electricity during heating season and appropriate prices of electricity, which are variable. Savings come out of the idea that the subtraction of steam for heating needs will be provided in the pipeline connecting Medium Pressure Turbine and Low Pressure Turbine. This steam has significantly lower parameters than the subtracted steam used as a heat source at the moment.

Annual savings of sold electricity at production cost and price of electricity determined by the Energy Regulatory Commission, [13], with prices of 2016 is 325,420EUR/season. It should be noted that with this amount is net profit from electricity production while the heating requirements of power plant are covered completely.

\section{CONCLUSION}

Based on the analysis, calculations and other findings, the following can be concluded:

- $\quad$ The existing heating installation is in very bad operational condition;

- $\quad$ The installation does not satisfy the necessary requirements for heat distribution to end users;

- The current installation is constantly reconstructed, adjusted according to current needs, without proper design solution;

- $\quad$ Valves, fittings, pumps and other ancillary equipment installed in the system during operation depends on the availability of spare parts (supplies), without taking care about the proper selection of equipment;

- $\quad$ The installation, particularly in the objects of the production unit - MINE, is in very poor situation and in terms of connectivity and also in condition;

- Because of the installation of hot water station for District Heating of Bitola, opportunity arises to connect the district heating system of the TPP Bitola, on future heating system for the city of Bitola. 
With the solutions proposed, optimum operating performance is achieved for the following circumstances:

- $\quad$ DH system of Bitola is in operation, while the heating system of buildings in REK Bitola works only when the district heating is in operation;

- $\quad$ DH system of Bitola is in operation, but the heating of buildings in REK Bitola can work independently of the district heating system;

- $\quad$ DH system of Bitola is not in operation and the existing heat source is used - basic and peak boilers of Block 1 and Block 2.

To achieve optimum performance in the heating system of the buildings in TPP Bitola, we propose a complete reconstruction of existing equipment, for which, a detailed technical and economic analysis and justification of the proposed solutions is provided.

The developed techno - economic analysis and the estimated value of investment costs with the relatively short return of investment (ROI) period, depending on the price of electricity and considered options, varies from 6.5 to 13 years, which makes reconstruction of the central heating system of the buildings in TPP Bitola economically justified.

\section{REFERENCES}

[1] -Energo system, Basic design (mechanical design) for hot water station with power of $200 \mathrm{MWh}$ and its connection to the system of TPP Bitola - phase I. Skopje, Macedonia. 2014.

[2] -Energo system, Basic design (mechanical design) for hot water station with power of $200 \mathrm{MWh}$ and its connection to the system of TPP Bitola - phase II. Skopje, Macedonia. 2014.

[3] V. Mijakovski, Z. Angelevski and C. Dimitrieska, Feasibility study for reconstruction and revitalization of central heating system for buildings in REK Bitola. Bitola, Macedonia: Faculty of technical sciences. 2016.

[4] T. Walski, W. Sharp and D. Shields, Predicting internal roughness in water mains: Report. Vicksburg, USA: US army engineer waterways experiment station. 1988.

[5] I.S. Kim, M. van der Helm and R.G. Ballinger, "Flow induced material degradation in power plant secondary systems: A review." Journal of the Korean nuclear society, vol. 30, no. 2, 1998, pp. 148-163.

[6] -EKONERG -Institut za energetiku i zaštitu okoliša, Techno - economic study for selection and concept of central district heating system for the municipalities of Bitola, Novaci and Mogila based on heat energy from REK Bitola. Zagreb, Hrvatska. 2012

[7] -American Society of Heat, Refrigerating and Air-Conditioning Engineers, ASHRAE Handbook: HVAC systems and equipment. Atlanta, USA. 2016.

[8] -American Society of Heat, Refrigerating and Air-Conditioning Engineers, ASHRAE Handbook: HVAC applications. Atlanta, USA. 2015.

[9] -Danfoss, Hydraulic regulators for temperature, flow and pressure - catalogue. Denmark. 2014.

[10] -Grundfos, Catalogues and software for selection of pumps. Denmark.

[11] -Funke, Catalogues of the plate heat exchangers producer. Germany.

[12] A.S. Lisyansky, Technical offer for arranging the district heating steam extractions at turbine plants K-235-130-3M, Units No 2 and No 3 "Bitola" power station, Macedonia. Sankt-Petersburg, Russia: OJSC Power Machines. 2011.

[13] -Energy regulatory commission of the Republic of Macedonia. . Available from: http://www.erc.org.mk/pages_en.aspx?id=158, accessed on 08.10.2016

Paper submitted: June 16, 2016

Paper revised: $\quad$ July 30,2016

Paper accepted: $\quad$ August 27, 2016
Copyrights $\odot 2017$ Society of Thermal Engineers of Serbia Published by the VINCA Institute of Nuclear Sciences, Belgrade, Serbia This is an open access article distributed under the CC BY-NC-ND 4.0 terms and conditions 